\title{
Lipopolysaccharide-induced sepsis induces long-lasting affective changes in the mouse
}

\author{
Seán T. Anderson ${ }^{a}$, Seán Commins ${ }^{a}$, Paul N. Moynagh ${ }^{\mathrm{b}}$, Andrew N. Coogan ${ }^{\mathrm{a}, *}$ \\ ${ }^{a}$ Department of Psychology, National University of Ireland Maynooth, County Kildare, Ireland \\ ${ }^{\mathrm{b}}$ Institute of Immunology, National University of Ireland Maynooth, County Kildare, Ireland
}

\section{A R T I C L E I N F O}

\section{Article history:}

Received 2 May 2014

Received in revised form 4 July 2014

Accepted 10 July 2014

Available online 22 July 2014

\section{Keywords:}

Sepsis

LPS

Behaviour

Cognition

Depression

Neuroinflammation

Hippocampus

\begin{abstract}
A B S T R A C T
Post-septic encephalopathy is a poorly understood condition in survivors of sepsis that is characterised by cognitive and affective impairments. In this study we have sought to better understand this condition by undertaking a comprehensive behavioural and cognitive assessment of mice who had previously survived sepsis. Mice were treated with lipopolysaccharide (LPS; $5 \mathrm{mg} / \mathrm{kg}$ ) and one month after this assessed on a battery of tests. Post-septic animals were found to display significantly more immobility in the tail suspension test and show a significantly decreased sucrose preference. Acute fluoxetine treatment reversed the increase in immobility in the tail suspension test in post-septic animals. Post-septic animals also showed less overall exploratory behaviour in the novel object recognition task and also showed increased anxiety-like behaviour in the elevated plus maze. Post-septic mice did not show signs of cognitive impairment, as assessed in the Morris watermaze, the 8-arm radial maze or on preference for the novel object in the novel object recognition task. Immunohistochemical analysis revealed significant upregulation of the microglial marker CD-11b, F4/80 and IBA- 1 in the hippocampus of post-septic animals, as well as significant downregulation of the plasticity-related immediate early gene products ARC and EGR1. We also observed a decrease in neural stem cell proliferation in the dentate gyrus of post-septic animals as judged by BrdU incorporation. Co-treatment with the NF- $\kappa B$ pathway inhibitor PDTC attenuated the long-lasting effects of LPS on most of the affected parameters, but not on neural stem cell proliferation. These results show that LPS-induced sepsis in the mouse is followed by longlasting increases in depressive- and anxiety-like behaviours, as well as by changes in neuroinflammatoryand neural plasticity-associated factors, and that attenuation of the severity of sepsis by PDTC attenuates many of these effects.
\end{abstract}

(c) 2014 Elsevier Inc. All rights reserved.

\section{Introduction}

Sepsis refers to a severe inflammatory response to infection co-occurring with alterations in at least two of the following parameters - body temperature, heart rate, respiratory rate and white blood cell count (Robertson and Coopersmith, 2006). Septic encephalopathy is a common complication of sepsis, occurring in up to $70 \%$ of patients (Papadopoulous et al., 2000) involving a deleterious mental state ranging from confusion to coma (Jacob et al., 2011). Structural and neuroinflammatory alterations persist in survivors, including reduced hippocampal volume and altered EEG activity, leading to cognitive and psychological impairments for years following recovery, and this condition is termed post-septic encephalopathy (Lazosky et al., 2010; Iwashyna et al., 2010;

\footnotetext{
* Corresponding author. Tel.: +35317086624.

E-mail address: andrew.coogan@nuim.ie (A.N. Coogan).
}

Davydow et al., 2012; Semmler et al., 2013; Winters et al., 2010; Ziaja, 2013). The aetiology of post-septic encephalopathy is not well understood and there are currently no successful treatments available.

While sepsis in humans is a heterogeneous condition, it is often modelled in rodents using the intraperitoneal injection of a high dose of the bacterial endotoxin lipopolysaccharide (LPS; Buras et al., 2005; Doi et al., 2009). Peripheral administration of highdose LPS leads to a potent inflammatory response, via TLR-4 binding and subsequent NF- $\kappa B$ pathway activation. These LPS treatments mimic many of the clinical features of sepsis and results in a hyper-inflammatory response, accompanied by depressed EEG rhythmicity, low blood pressure, oxidative stress, multiple organ failure and a significant mortality rate (Chang et al., 2013; Lin et al., 2010; Okazaki et al., 2014). Following recovery from the acute effects of LPS-induced sepsis, an increased level microglial activation persists in the CNS, accompanied by 
prolonged over-expression of pro-inflammatory cytokines as well as time and dose dependent neuronal degeneration (Bossù et al., 2012; Weberpals et al., 2009; Qin et al., 2007).

In addition to persistent neuroimmunological changes, there have been a number of studies examining cognitive and affective parameters following recovery from both LPS-induced, and cecal ligation and puncture (CLP)-induced sepsis. There is considerable variance in the behavioural changes present in post-septic animals depending on both the method of sepsis induction and the latency to test behaviour following recovery from sepsis. Within the domain of learning and memory, post-septic animals have shown cognitive impairments across tasks such as the step-down passive avoidance task, the radial arm maze, and novel object recognition tasks (Barichello et al., 2007; Cassol-Jr et al., 2010, 2011; Semmler et al., 2007; Weberpals et al., 2009). Ten months after LPS-induced sepsis rats show no differences in the elevated plus maze or Morris watermaze, although they exhibit reduced exploration and recognition of a novel object in the open field test (Bossù et al., 2012). Sepsis survivor mice also show alterations in their circadian rhythms, and in their circadian responses to subsequent LPS challenge (O'Callaghan et al., 2012; Anderson et al., 2013). Postseptic animals have also been shown to display increased levels of depressive-like behaviour including both anhedonia and behavioural despair (Comim et al., 2010; Tuon et al., 2008) as well as anxiety-like behaviour in the elevated plus maze ten days after CLP (Calsavara et al., 2013). These affective changes may be linked to the growing evidence for a neuroimmune basis to mood disorders such as major depressive disorder (Berk et al., 2013; Miller et al., 2009).

The aim of this study was to comprehensively characterize the cognitive and affective state of sepsis-survivor mice one month after LPS induced sepsis, as well as assessing changes in neuroimmune markers and neurogenesis in post-septic animals.

\section{Methods}

\subsection{Animals}

For the purpose of all experiments male C57BL/6 mice (Charles River, Kent, UK) aged between 8 and 16 weeks were used. Animals were group housed in a 12:12 light:dark cycle for 2 weeks prior to LPS administration. Food and water were available ad libitum unless animals were on a food restriction protocol, temperature was $21 \pm 1{ }^{\circ} \mathrm{C}$ and humidity was $50 \pm 10 \%$. Animals remained housed in groups of $2-4$ in polypropylene cages $(33 \mathrm{~cm}$ long $\times 15 \mathrm{~cm}$ wide $\times 13 \mathrm{~cm}$ high) with wood chip bedding and environmental enrichment (shredded paper and cardboard tubes). All procedures were approved by the Research Ethics Committee, National University of Ireland Maynooth, and were licensed by the Department of Health and Children, Ireland under statutory instrument (S.I.) No. 543 of 2012 and the European directive 2010/63/EU.

\subsection{Drug treatments}

All injections were prepared fresh on the treatment day, and given intraperitoneally in a final injection volume of $0.1-0.15 \mathrm{ml}$. $0.9 \%$ sterile saline was made up fresh for control injections, while lipopolysaccharide (serotype 0111.B4, Sigma Ireland; Qin et al., 2007) was made up to a $5 \mathrm{mg} / \mathrm{kg}$ dose in sterile saline. PDTC (Sigma Ireland) was administered in a $200 \mathrm{mg} / \mathrm{kg}$ dose (Liu et al., 1999) $10 \mathrm{~min}$ before LPS treatment while $20 \mathrm{mg} / \mathrm{kg}$ fluoxetine (Tocris Bioscience, Bristol, UK) was administered $90 \mathrm{~min}$ before behavioural testing. Mortality and significant moribundity requiring euthanasia occurred in approximately $10 \%$ of animals following the induction of sepsis. Following sepsis induction animals were individually assessed in terms of weight, activity in the homecage, general appearance, behaviour and altered breathing at 1, 4, 24 and $48 \mathrm{~h}$ as well as at one week post LPS-administration. Animals were scored between 0 and 5 on each parameter with scores then totalled. To assess the number of neural precursor cells in the hippocampus mice which had one month previously undergone sepsis-induction were injected i.p. with $50 \mathrm{mg} / \mathrm{kg}$ BrdU (Sigma Ireland) and transcardially perfused $24 \mathrm{~h}$ later.

\subsection{Behavioural experiments}

Behavioural testing began one month after sepsis induction. Each animal underwent no more than four tests, with less stressful tests (open field, sucrose preference, etc.) preceding more stressful tests (elevated plus maze, forced swim test, tail suspension test). All animals only underwent one aversive test.

\subsubsection{Marble burying task}

As mice may bury novel objects which they find anxiety inducing, the number of marbles buried during the test served as the dependent measure of anxiety. Animals were placed in an isolated testing arena $(26 \mathrm{~cm}$ length $\times 20 \mathrm{~cm}$ width $\times 27 \mathrm{~cm}$ high) filled with roughly $6 \mathrm{~cm}$ of wood chip bedding for $30 \mathrm{~min}$ with marbles arranged in four rows of three, evenly spaced from each other and the sides of the test cage (Deacon, 2006). After 30 min mice were removed and marbles were considered buried where at least $2 / 3$ of their surface was covered with woodchip. The dependent variable from this test was the number of marbles buried.

\subsubsection{Open field test}

Open field testing occurred in an arena of diameter $100 \mathrm{~cm}$. Trial length was $300 \mathrm{~s}$ during which distance moved, velocity in $\mathrm{cm} / \mathrm{s}$ and time spent moving as well as time in the inner and outer 50\% were automatically tracked with Ethovision 3.1 software (Ethovision 3.1; Noldus Information Technology, Leesburg, VA). Time spent in the inner corridor versus the outer corridor of the arena is a measure of anxiety-like behaviour while distance, velocity and time spent moving are indexes of general locomotor behaviour.

\subsubsection{Hyponeophagia test}

Measuring the time it takes for rodents to sample a novel food in a novel situation is taken as a measure of anxiety-like behaviour. Testing occurred in a large transparent plexiglass container (26 length $\times 20$ width $\times 13.5 \mathrm{~cm}$ high) placed on a white surface using existing methodology with chocolate as the novel food (Deacon, 2011). Animals were given up to 3 trials of $4 \mathrm{~min}$, after which testing for that animal stopped and they were given a score of $720 \mathrm{~s}$ if they had not yet eaten.

\subsubsection{Sucrose preference test}

Preference for a sucrose solution over water functions as a dependent measure of anhedonia Following a method set out in Strekalova et al. (2004) bottles were filled with either animals' standard drinking water or $1 \%$ sucrose in the animals standard drinking water, lids securely taped in place to minimize spillage and weighed. Cages were modified to accommodate two bottles, and food was placed in both sides. Mice were then given a free choice between either tap water, or a $1 \%$ sucrose in tap water solution for $24 \mathrm{~h}$. After $12 \mathrm{~h}$ had passed, the position of the two bottles was switched, in order to control for a side preference in drinking behaviour. After $24 \mathrm{~h}$ had passed, the bottles were then weighed to measure how much liquid was consumed, and sucrose preference was calculated as [sucrose consumed/(water consumed + sucrose 
consumed)] for each mouse. The data of animals were removed if they were found to have liquid in their cages.

\subsubsection{Forced swim test}

This test measures depressive-like behaviour with immobility taken as the dependent measure of behavioural despair. Animals were placed singly in a 2 litre clear plexiglass beaker $(12.5 \mathrm{~cm}$ diameter $\times 23.5 \mathrm{~cm}$ height) filled to a height of $12 \mathrm{~cm}$ with $1.25 \mathrm{l}$ water $\left(25^{\circ} \mathrm{C}\right)$ such that their tails could not touch the bottom of the beaker. Following the method of Porsolt et al. (1997) each test lasted six minutes, with the immobility (absence of movement except leg kicks to stay afloat) scored in the final four minutes only.

\subsubsection{Tail suspension test}

This is another test of behavioural despair. According to a previously used protocol (Steru et al., 1985) mice were attached to a support raised to a height of $121 \mathrm{~cm}$ using tape placed $1 \mathrm{~cm}$ from the tip of their tales for six minutes. Mice were suspended for six minutes each, with immobility (complete absence of movement) being recorded throughout the entire six minutes. For fluoxetine treatments, on the experimental day 1 animals were injected with $0.9 \%$ sterile saline $90 \mathrm{~min}$ before undergoing the tail suspension test. Two weeks later on experimental day 2 animals were injected with $20 \mathrm{mg} / \mathrm{kg}$ fluoxetine dissolved in sterile saline $90 \mathrm{~min}$ prior to repeating the test.

\subsubsection{Novel object recognition test}

Animals were first habituated to an arena of $50 \mathrm{~cm}$. Each animal underwent 5 trials lasting two minutes each. During the first four trials, animals were habituated to two objects. Between each trial the animal was removed while the objects and arena were cleaned with $70 \%$ ethanol solution. On the fifth trial one familiar object was replaced with a novel object. The objects had previously been examined for preference with no differences being observed. These objects were pseudo-randomized so that each object could function as either a familiar object or the novel object in any given session. This randomization was balanced across each group. Animals were measured on their time touching, and number of nose touches for each object during each trial. This is typically a test of working memory with novel object recognition, the dependent variable, calculated as [time exploring the novel object/(time exploring the novel object + time exploring the familiar object)] or [number of touches on the novel object/(number of touches on the novel object + number of touches on the familiar object)]. In this experiment time touching and number of touches on the familiar and novel objects were also taken as measures of exploratory behaviour.

\subsubsection{Working memory watermaze}

Testing followed the protocol of Vorhees and Williams (2006) in a pool of diameter $100 \mathrm{~cm}$, with water $21 \pm 1^{\circ} \mathrm{C}$. A rectangular white card $(55 \times 81 \mathrm{~cm})$ to the west of the pool was visible to the mouse, and there were lights in the northeast and southeast. Each animal underwent twenty-eight sixty-second trials over seven sessions (4 trials/session). Two sessions took place per day such that there was four hours between the first and second session, then twenty hours between the second and third session and so on. Each mouse was placed into the pool at the northeast, northwest, southeast and southwest positions in a pseudo-random order. In session one an invisible platform of diameter $9 \mathrm{~cm}$ was submerged $0.5 \mathrm{~cm}$ below waterlevel in the northwestern quadrant of the pool. This platform was moved clockwise from quadrant to quadrant on each subsequent session. The mouse was returned to a cage for $10 \mathrm{~s}$ between trials. Escape latency was defined as the time it took the mouse to mount the hidden platform. All experiments were tracked using a video camera and Ethovision
3.1 software (Ethovision 3.1; Noldus Information Technology, Leesburg, VA). Escape latency, distance travelled and velocity $(\mathrm{cm} / \mathrm{s})$ were measured throughout the trial. Escape latency was the primary dependent variable of interest functioning as a measure of working memory. Savings was calculated as the difference in escape latency between swim one and swim two.

Testing occurred in the same maze conditions previously described in the section above. Each animal underwent 4 trials per session for 6 sessions. Two sessions took place per day such that there was four hours between the first and second session, then twenty hours between the second and third session and so on. Each mouse was placed into the pool at the northeast, northwest, southeast and southwest positions in a pseudo-random order. In all sessions an invisible platform of diameter $9 \mathrm{~cm}$ was submerged $0.5 \mathrm{~cm}$ below water level in the North-Eastern quadrant of the pool. The mouse was returned to a cage for $10 \mathrm{~s}$ between trials. Escape latency, distance travelled and velocity $(\mathrm{cm} / \mathrm{s})$ were measured throughout the trials. Escape latency was the primary dependent variable of interest functioning as a measure of spatial memory acquisition.

\subsubsection{Radial 8-arm maze}

This is a test of spatial working memory. Animals were placed on an $80 \%$ restricted diet for five days before the first day of experimental testing followed by a $60 \%$ restricted diet throughout the duration of the experiment. The maze consisted of a centre area of diameter $13.5 \mathrm{~cm}$, from which 8 arms extended of length $34.5 \mathrm{~cm}$, width $5 \mathrm{~cm}$ and height $13.5 \mathrm{~cm}$. Similar to previously used methodology (Janitzky et al., 2011), all eight arms of the maze were baited with a food reward (chocolate). Trials were of five minutes length, unless the animals successfully consumed all of the bait. The apparatus was wiped down with $70 \%$ ethanol between all trials to remove the previous animals' odour. Each animal underwent one trial per day, for fourteen days. Entrances to an arm were counted when all four of the mouse's paws were within the arm. The trial was ended once the animal either consumed all rewards or once five minutes had passed. The primary dependent variables were latency to complete the maze, a measure of learning, and the number of repeat entries to arms where bait was already consumed, taken as a measure of working memory errors.

\subsubsection{Elevated plus maze}

This test assesses anxiety-like behaviour by measuring time spent in the open arms and number of entries to the open arms as primary dependent variables. The elevated plus maze was conducted in accordance with the protocol set out by (Walf and Frye, 2007). The maze consisted of a centre area of diameter $13.5 \mathrm{~cm}$, from which four arms extended of length $34.5 \mathrm{~cm}$, width $5 \mathrm{~cm}$. Two arms were open without walls, while the other two were enclosed by high walls. Entrance to an arm was counted where all four of an animals' paws were within the arm. Animals underwent one five-minute testing session each.

\subsection{Immunohistochemistry}

At least one week after their last behavioural task (so typically 2 months after the LPS treatment) mice were anaesthetized with $0.1 \mathrm{ml}$ sodium pentobarbital (Euthatal, Merial Animal Health, UK), following which they were perfused transcardially with $0.9 \%$ saline, and then $4 \%$ paraformaldehyde (Sigma Ireland) in $0.1 \mathrm{M}$ phosphate buffer (PB), pH 7.4 at $4{ }^{\circ} \mathrm{C}$. Brains were then cryoprotected in $0.1 \mathrm{M} \mathrm{PB}$ containing $30 \%$ sucrose, frozen and sectioned coronally at $30 \mu \mathrm{m}$. Immunohistochemistry followed a standard Avidin-Biotin Complex/Nickel DAB colorimetric protocol (Beynon et al., 2009). To control for inter-run variability all sections for individual anti-bodies were reacted in the same run and developed for 
an equal amount of time. Sections were stained for microglial markers (CD11b, F4/80. IBA-1), astrocytes (GFAP), cytokines (IL-1 $\beta$, TNF- $\alpha$, IL-6), iNOS, NF- $\kappa B$ pathway components (p-IKK, p-IKB), IEGs (ARC, EGR1) and marker of cell proliferation (BrdU). Details of the primary antibodies used can be found in Supplemental Table 1. Photomicrographs of sections were taken using a digital camera connected to an Olympus BX-51 light microscope under constant light intensity. Morphology and number of active microglia stained with IBA- 1 were assessed under $100 \times$ magnification within a pre-defined area while for ARC the number of clearly stained immunoreactive cells per area per section were counted via microscope, and for all other antibodies image analysis software (ImageJ 1.43, NIH, USA) was used to binarize and calculate integrated optical density for each area of interest (Anderson et al., 2013). For each method between 4 and 6 sections of the mid dorso-ventral level of the hippocampus were analysed. Hippocampal sections were assessed across five areas of interest - the dentate gyrus granule cell layer ( $\mathrm{DgGr}$ ), the dentate gyrus polymorphic cell layer (DgPo), CA1, CA2 and CA3, with the entire section of interest analysed for each section (Franklin and Paxinos, 1997). For BrdU immunohistochemistry the protocol was carried out as above, but with an additional DNA denaturation step involving incubation of sections in $1 \mathrm{M} \mathrm{HCl}$ for $30 \mathrm{~min}$ at $45^{\circ} \mathrm{C}$ (Wojtowicz and Kee, 2006).

\subsection{Data analysis}

All data values are given as mean \pm SEM. Data was analysed in IBM SPSS version 20. Inferential statistical analysis was via factorial between groups or mixed between-within groups ANOVAs and $t$ tests as appropriate (paired or independent). $P<0.05$ was deemed statistically significant with appropriate Bonferroni correction applied for multiple comparisons.

\section{Results}

\subsection{LPS-induced sepsis induces depressive-like and anxiety-like behaviours but no cognitive impairment}

First we examined the performance of animals that had previously undergone sepsis or controls on a battery of behavioural tests. On the sucrose preference test we found that post-septic animals showed significantly less preference for sucrose than controls (preference ratio of $0.69 \pm 0.04$ in post-septic animals compared to $0.78 \pm 0.02$ in controls; independent $t$-test, $t_{18}=2.3, P<0.05$; Fig. 1A). We found that post-septic animals showed no differences in immobility in the forced swim test (Fig. 1B; independent $t$-test, $t_{30}=-0.68, P=0.50$ ) but did show significantly more immobility on the tail suspension test $(210 \pm 9 \mathrm{~s}$ immobile for the post-septic animals compared to $158 \pm 10 \mathrm{~s}$ for control animals; independent $t$-test, $t_{29}=-3.95, P<0.001$, Fig. $\left.1 \mathrm{C}\right)$. We next examined the effect of acute fluoxetine treatment on immobility in the tail suspension test in control and post-septic animals. We found that while fluoxetine did not alter immobility levels in control animals (Fig. 1D), it significantly reduced the amount of immobility in post-septic animals ( 2 way mixed between-within ANOVA indicates a significant sepsis $\times$ fluoxetine interaction, $\mathrm{F}_{1,18}=4.52, P<0.05$ and post hoc analysis reveals that in the post-septic group fluoxetine treatment significantly reduced immobility, $t_{9}=2.92, P<0.05$; Fig. $1 \mathrm{E}$ ).

We then examined a cohort of animals on the elevated plus maze, a commonly used test of anxiety-like behaviour in rodents. We found that post-septic animals made significantly fewer entries into the open arms than did the control animals ( $5.5 \pm 0.9$ entries for the post-septic animals compared to $9.1 \pm 0.9$ entries for controls; independent $t$-test, $t_{22}=2.79, P<0.05$; Fig. 2). When examined in the open field test (S1), the marble burying task and the hyponeophagia task (all tests of anxiety-related behaviour, S2) there were no significant differences in performance detected between the control and post-septic groups. Animals were then tested on an object recognition task. This task can be used to assess working memory as well as generalised exploration behaviour. In terms of working memory we found no differences between the control and post-septic animals in their exploration of the novel object compared to the familiar object (Fig. 3A). However we found that post-septic animals explored both the familiar and the novel object significantly less than control animals (independent $t$-test, $t_{35}=2.12, P<0.05$ and $t_{35}=2.51, P<0.05$ for time spent with familiar and novel objects respectively, Fig. $3 \mathrm{~B}$ and $\mathrm{C}$ ).

Performance on a working memory version of the radial arm maze was examined. Here we found that post-septic animals performed as well as control animals on the parameters examined. For example, using the number of arm entries until a previouslyentered arm is re-entered as a measure of working memory we find a significant effect of time (mixed between-within subjects ANOVA, $\left.F_{13,236}=81, P<0.001\right)$ but no main effect of treatment $\left(F_{1,22}=0.41, P=0.42\right)$ and no significant interaction between treatment and time $\left(F_{13,286}=0.475, P=0.97\right.$; Fig. $\left.4 \mathrm{~A}\right)$. Examining latency to complete the task as the dependent variable, there was also a main effect of time $\left(F_{13,236}=11, P<0.001\right)$, but no main effect of treatment $\left(F_{1,22}=0.41, P=0.53\right)$ nor was there a significant interaction between time and treatment $\left(F_{13,286}=0.46, P=0.94\right.$; Fig. $\left.4 \mathrm{~B}\right)$. We further examined both working and reference spatial memory in control and post-septic animals using the Morris Water Maze. Using the spatial working memory version of this task we did not observe any differences in performance between control and post-septic animals (Fig. 4C and D). Further, on the reference memory version of the task we did not find any significant differences in acquisition between the post-septic animals and the control animals as assessed by escape latency across the 6 sessions of testing (from mixed between-within subjects ANOVA there was a main effect of time on escape latency $F_{5,65}=24.9, P<0.001$, but no effect of treatment $\left(F_{1,13}=0.14, P=0.74\right)$ or interaction between treatment and time $\left.\left(F_{5,65}=1.11, P=0.36\right)\right)$. Therefore it appears that the post-septic animals performed equally well on tests of working and reference spatial memory/learning.

\subsection{Long-lasting neuroimmune changes in post-septic mice}

To examine neuroinflammatatory processes that may occur in the post-septic brain we examined immunohistochemical staining for a number of microglial markers in the hippocampus. We found that levels of F4/80 and Cd-11b, and the number of IBA-1 expressing cells with a morphology associated with activated microglia, were upregulated in the hippocampus of the post-septic animals compared to controls (for example in the CA1 independent $t$-tests show that $t_{13}=-4.45, P<0.01, t_{13}=-2.46, P<0.05$ and $t_{6}=-2.46$, $P<0.05$ for $\mathrm{F} 4 / 80, \mathrm{Cd}-11 \mathrm{~b}$ and IBA-1 respectively; Fig. 5). There were no changes in expression of the astrocytic marker GFAP in the hippocampus, nor any observed changes in tumour necrosis factor- $\alpha$, interleukin- $1 \beta$, inducible nitric oxide synthase, interleukin- 6 , components of the NF-kB signalling pathway phosphorylated-I $\kappa \mathrm{B}$ and phosphorylated-IKK (Supplementary Fig. 3). Further immunohistochemical analysis was undertaken for markers of neural plasticity and neural stem cell progenitor proliferation. The number of cells in the subgranular zone of the dentate gyrus that incorporated BrdU after a $24 \mathrm{~h}$ pulse was significantly decreased in post-septic animals compared to controls (independent $t$-test, $t_{9}=3.60, P<0.01$; Fig. $6 \mathrm{~A}$ ). The number of cells in the dentate gyrus expressing the synaptic plasticity related immediate early gene ARC was also significantly decreased in the post-septic animals (independent $t$-test, $t_{12}=2.31, P<0.05$, Fig. 6B; ARC was 
A

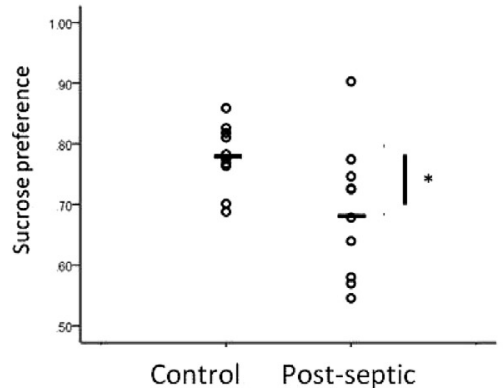

C

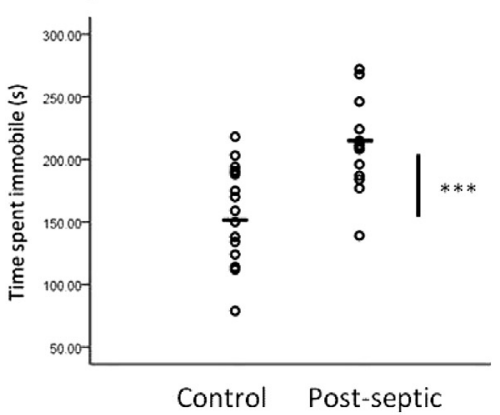

B

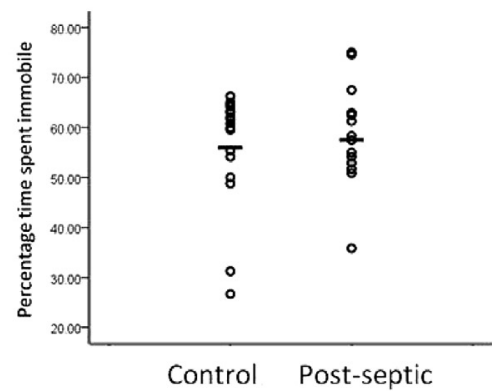

E
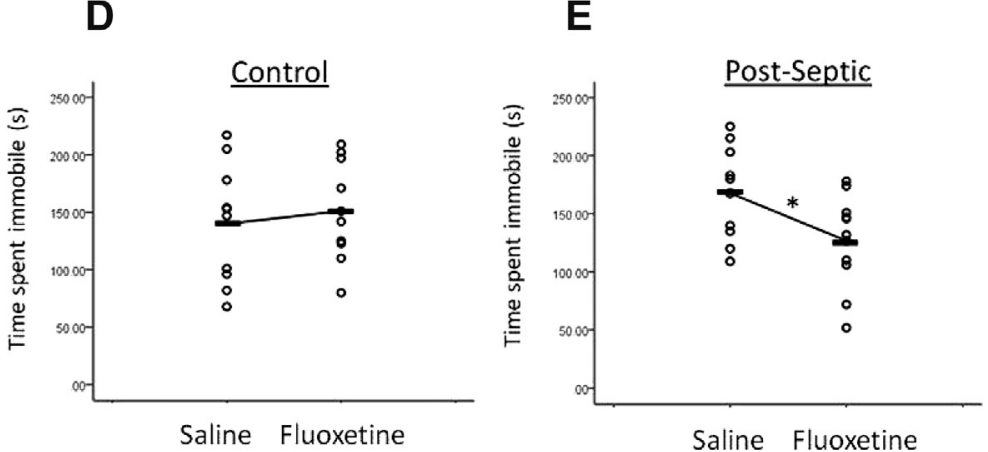

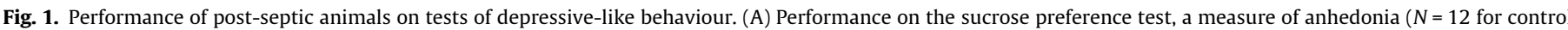

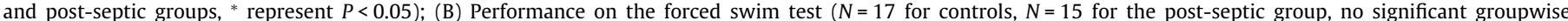

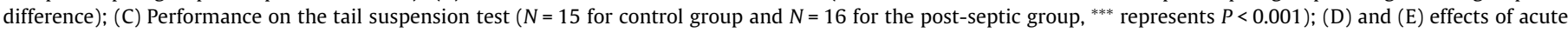

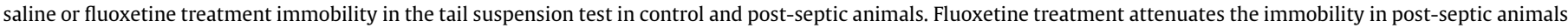
( ${ }^{*}$ represents $P<0.05$ between saline and fluoxetine treatments; $N=11$ for controls and $N=10$ for post-septic animals).

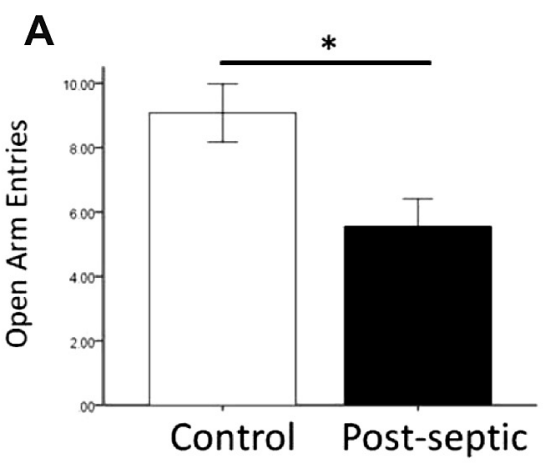

C

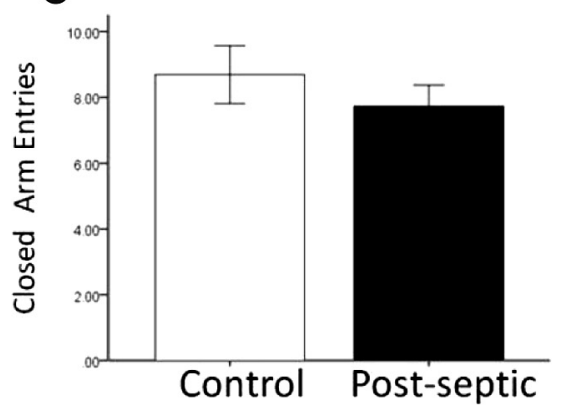

B

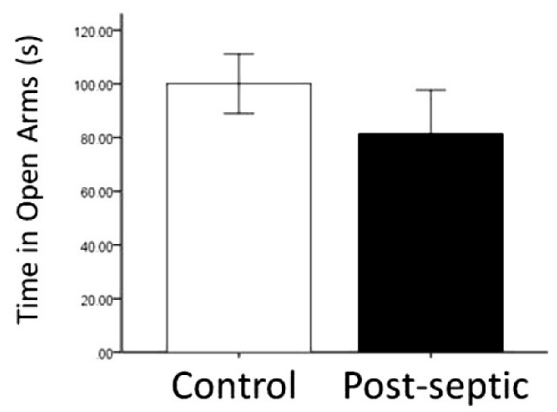

D

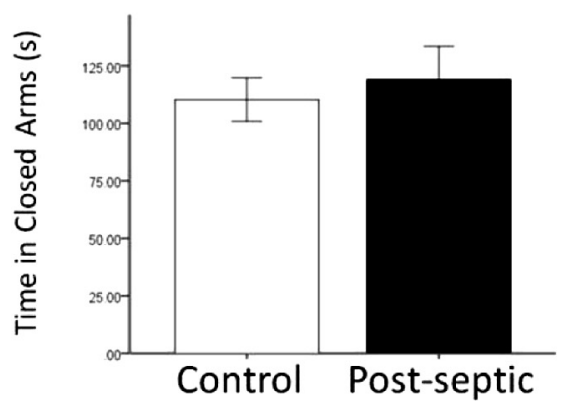

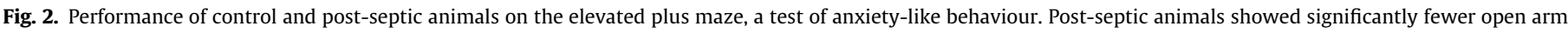

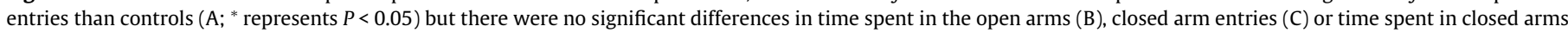
(D). $N=13$ for the control group and $N=11$ for the post-septic group.

not found to be expressed in other hippocampal subregions). Expression of EGR1, another immediate early gene product associated with neural plasticity, was found to be significantly decreased in the dentate gyrus and the CA1 of post-septic animals (independent $t$-test, $t_{6}=4.3, P<0.01$ and $t_{6}=2.8, P<0.05$ for the DG and CA1 respectively; Fig. $6 \mathrm{C}$ ). 

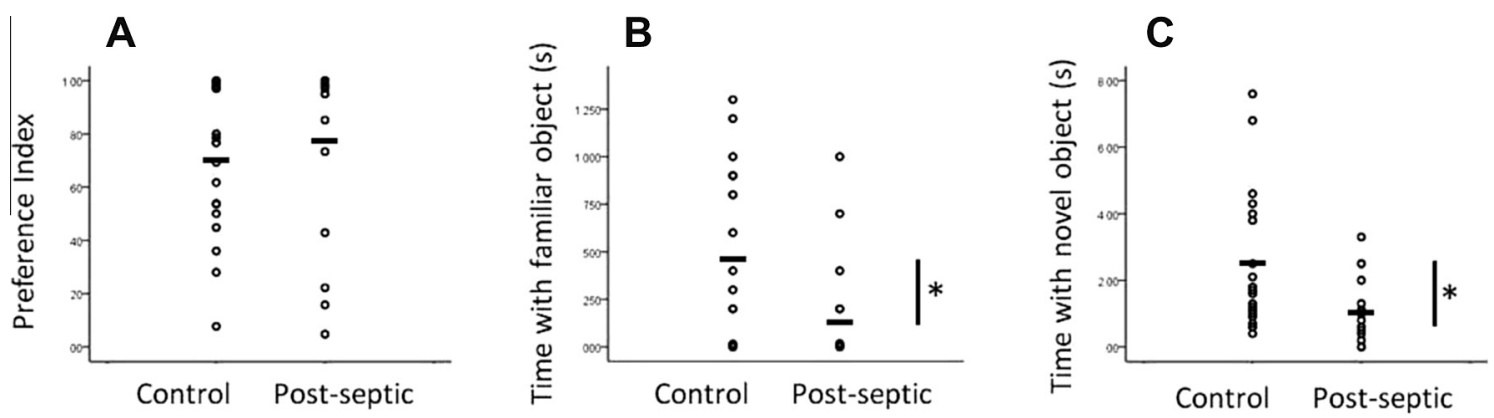

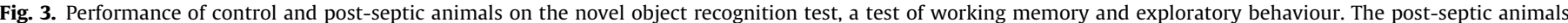

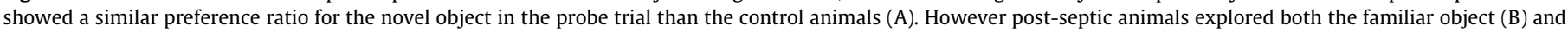
the novel object (C) significantly less. * represents $P<0.05, N=20$ for the control group and $N=18$ for the post-septic group.

A

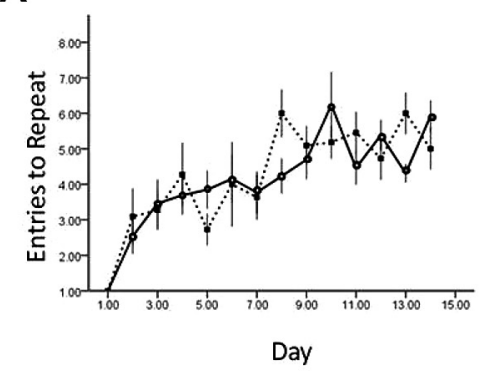

C

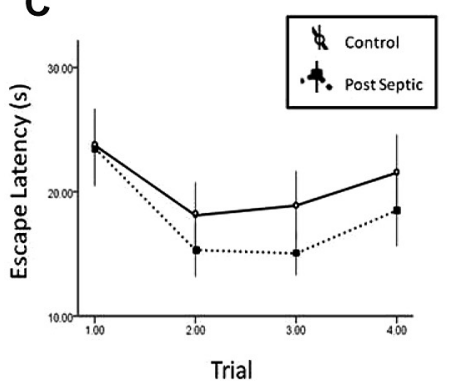

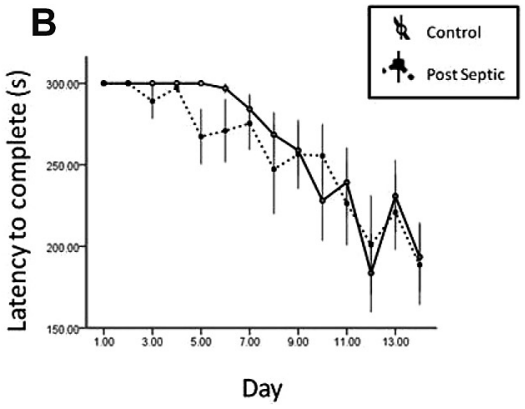
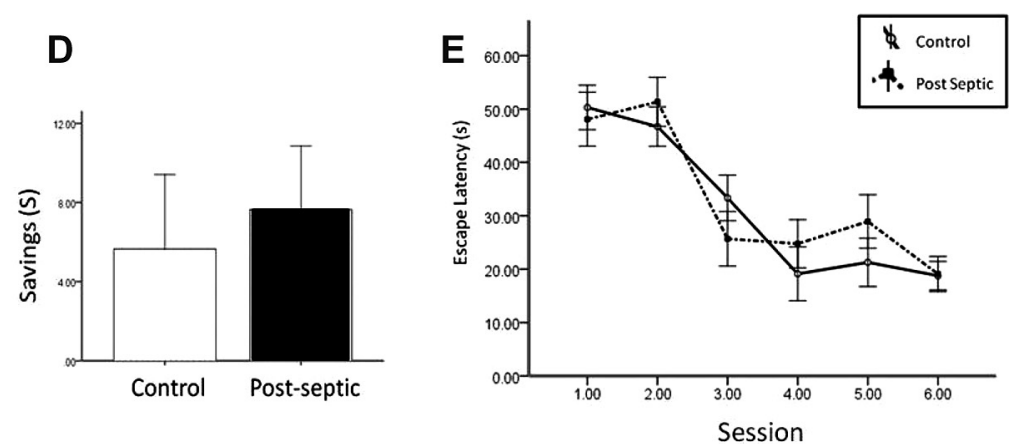

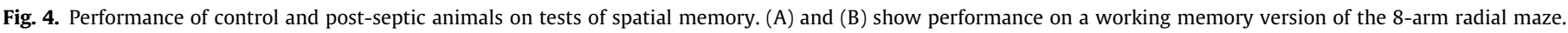

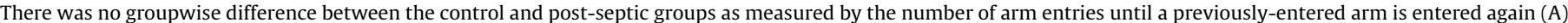

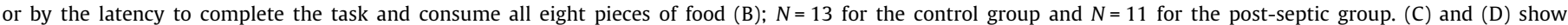

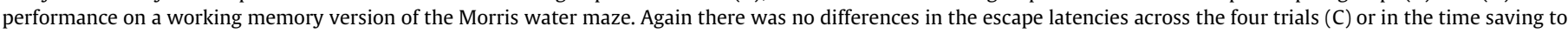

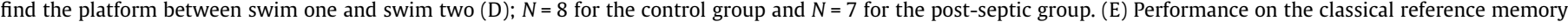
version of the Morris water maze. There was no significant groupwise difference on this spatial memory task; $N=8$ for controls and $N=7$ for post-septic animals).

\subsection{PDTC ameliorates behavioural and neuroimmune alterations associated with LPS-induced sepsis}

We next undertook experiments in which we examined whether the chronic effects described in post-septic animals could be ameliorated by co-treatment with PDTC (an inhibitor of the NF$\kappa B$ pathway) at the time of LPS administration. We found that PDTC treatment alone (at $200 \mathrm{mg} / \mathrm{kg}$ ) induced an acute adverse reaction (sedation, lack of responsiveness) but this effect resolved within a number of hours (Fig. 7A). Co-treatment with LPS and PDTC produced a less severe sepsis than produced with saline and LPS. Three-way mixed between-within subjects ANOVA $($ PDTC $\times$ LPS $\times$ Time) indicates significant main effects of time, PDTC and LPS treatment $(P<0.01$ for all), as well as Time $\times$ PDTC and Time $\times$ LPS interactions $(P<0.001)$ and a Time $\times$ PDTC $\times$ LPS interaction $(P<0.05)$. Therefore it appears that PDTC treatment attenuates the sepsis clinical score induced by LPS. Animals were later assessed on the behavioural tasks that had previously revealed differences between the treatment groups. When analysed on the tail suspension test via between groups $2 \times 2$ factorial ANOVA, there was a significant interaction between LPS and PDTC treatment on time spent immobile $\left(F_{1,37}=9.1, P<0.001\right.$; Fig. $\left.7 \mathrm{~B}\right)$. Likewise when animals were examined on the elevated plus maze there was a significant PDTC $\times$ LPS interaction $\left(F_{1,37}=6.21\right.$, $P<0.05$; Fig. 7C), and when they were examined for sucrose preference there was also a significant interaction between LPS and PDTC treatments $\left(F_{1,37}=5.35, P<0.05\right.$; Fig. 7D). When animals were examined for time exploring both the novel and the familiar object in the object recognition task there was a main effect of LPS treatment on time spent with both objects $\left(F_{1,37}=11.1, P<0.01\right.$; Fig. 7E) but no main effect of PDTC treatment $(P=0.14)$ nor a significant interaction between PDTC and LPS treatments on time spent with both objects $(P=0.61)$.

Brains from animals treated with combinations of LPS/vehicle and PDTC/vehicle were then analysed for BrdU, EGR1 and IBA-1 immunostaining (ARC was not examined due to technical 

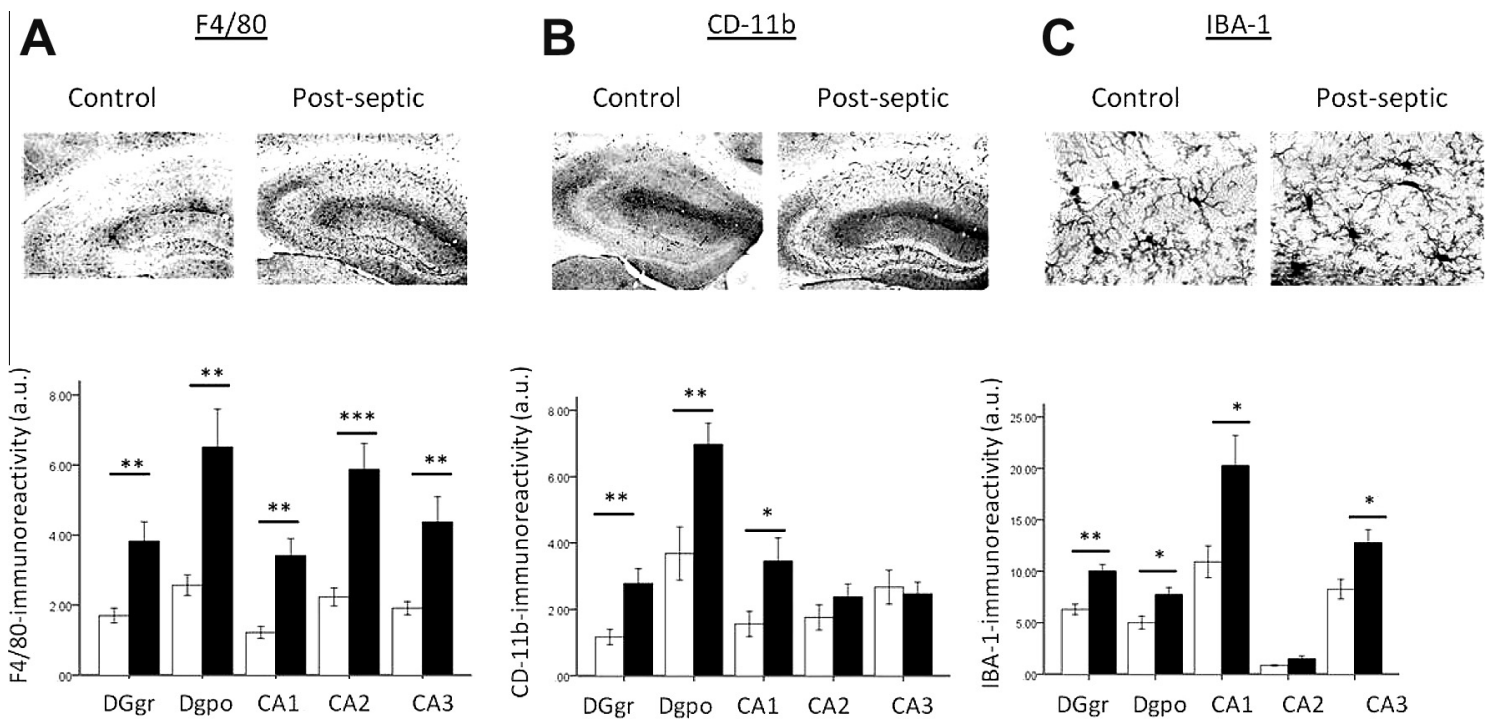

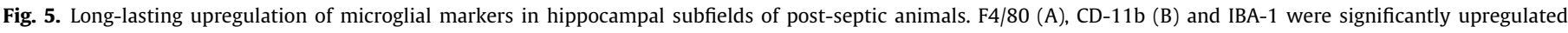

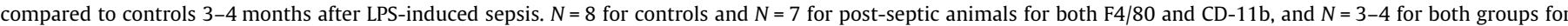

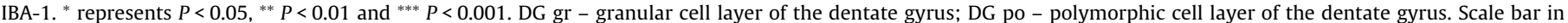
photomicrographs $=100 \mu \mathrm{m}$.
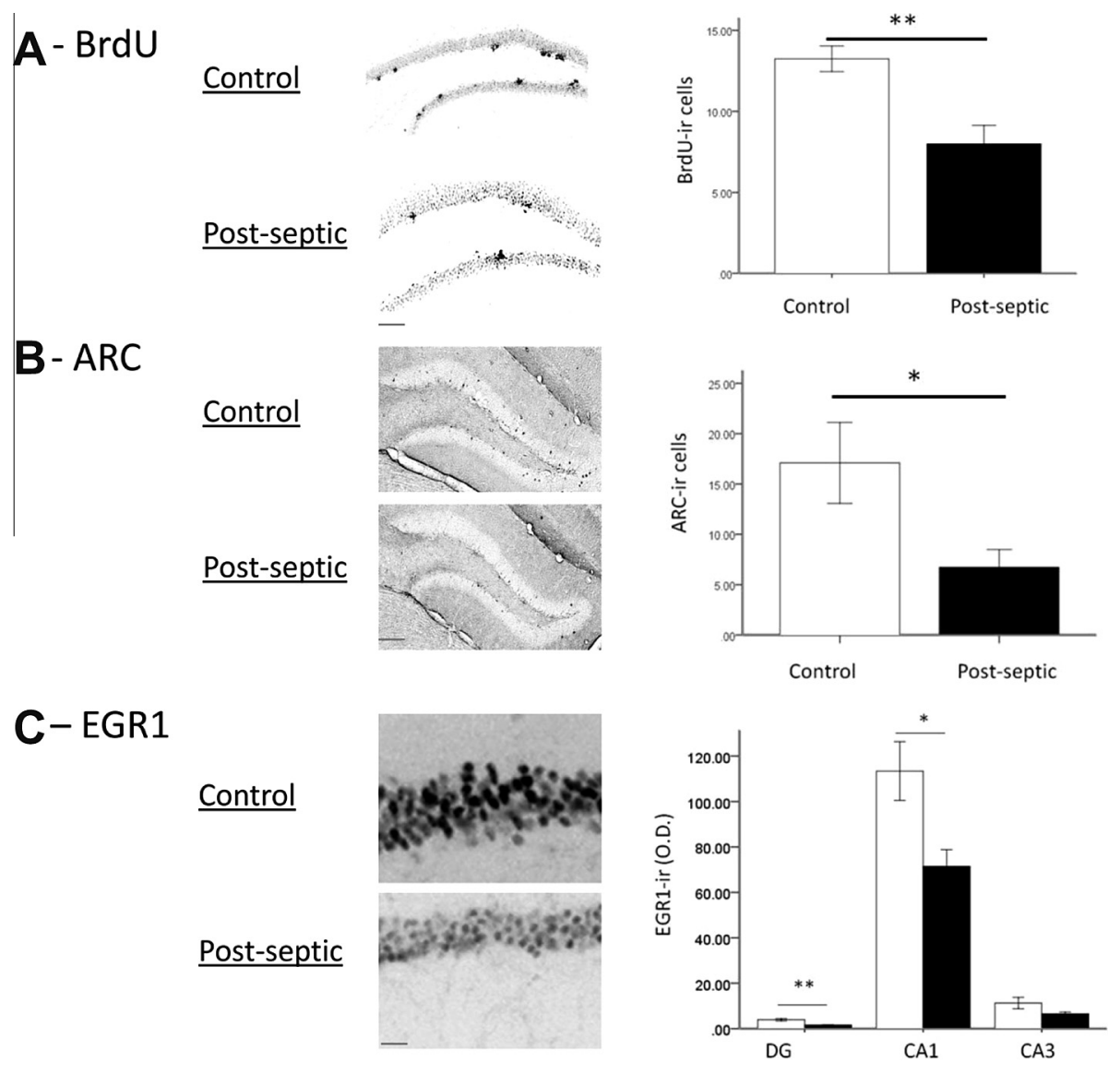

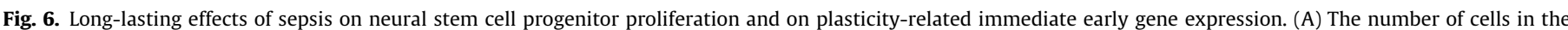

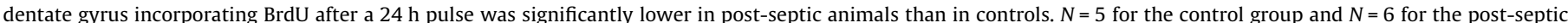

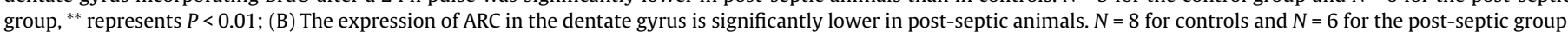

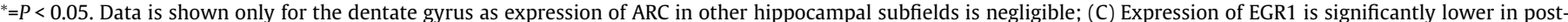

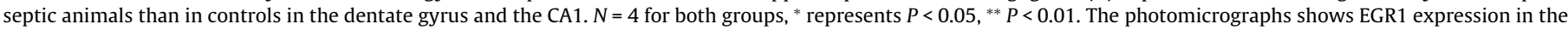
pyramidal cell layer of the CA1. 
A

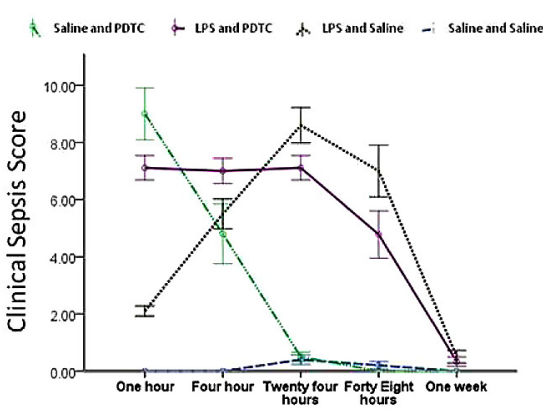

C

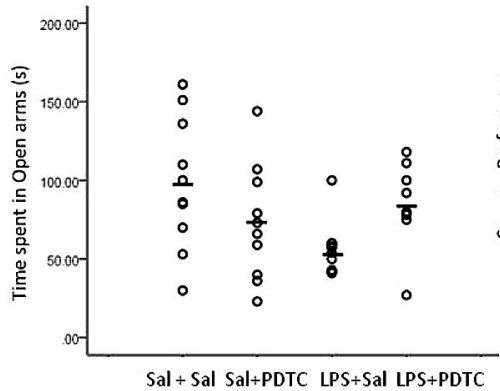

D

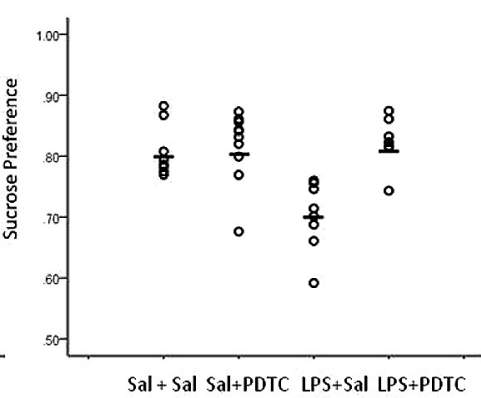

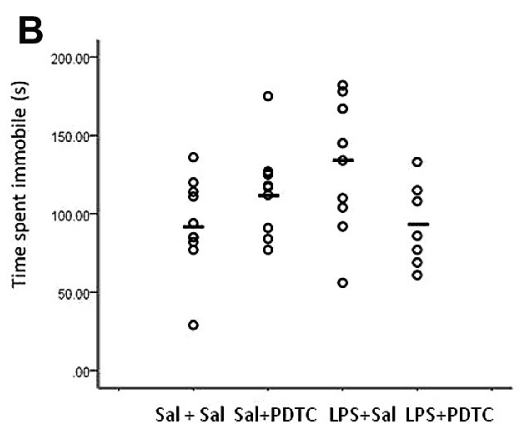

E

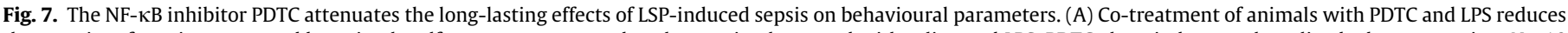

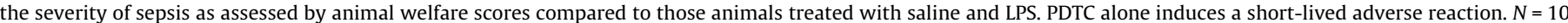

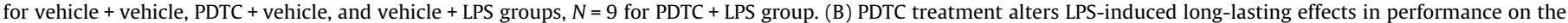

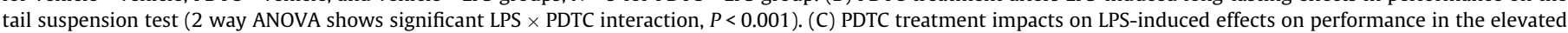

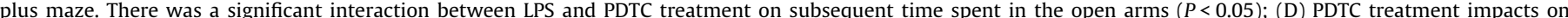

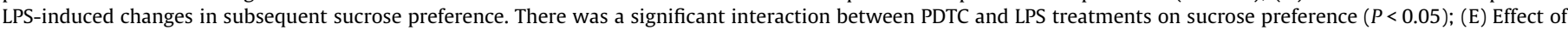

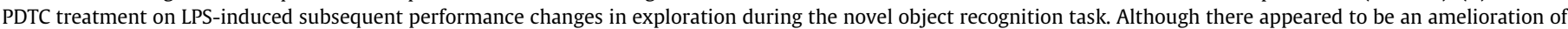
LPS-induced decreases in object exploration in animals also treated with PDTC, there was not a significant LPS $\times$ PDTC treatment effect $(P>0.05)$.

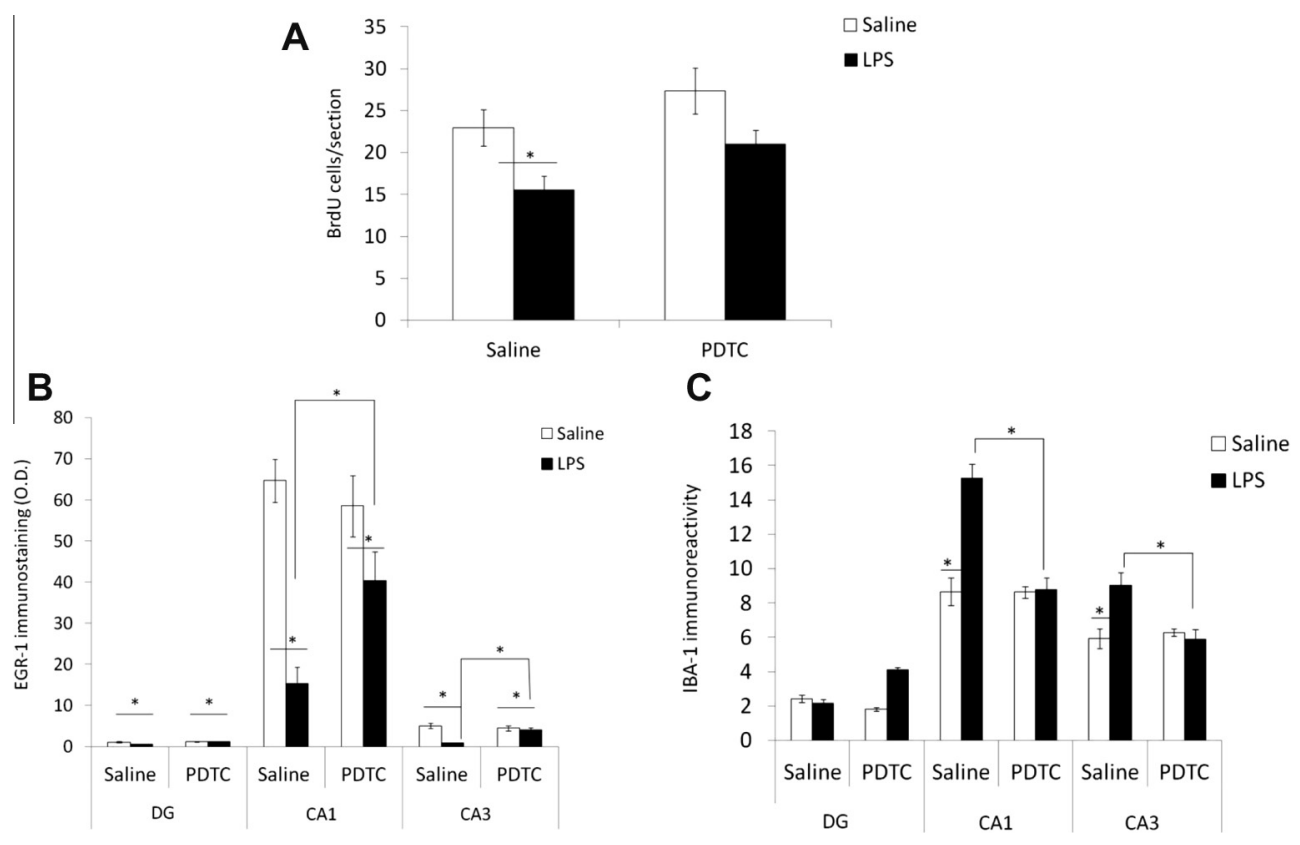

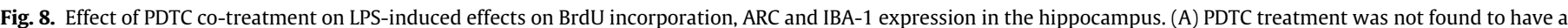

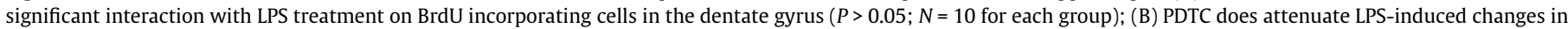

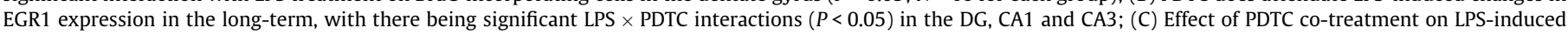
changes on subsequent IBA-1 expression. There were significant interactions between LPS and PDTC treatment in the CA1 and the CA3.

difficulties). When BrdU was examined there was a significant main effect of LPS treatment $\left(2 \times 2\right.$ ANOVA; $F_{1,37}=7.2, P<0.05$; Fig. $8 \mathrm{~A})$ but no main effect of PDTC treatment $(P=0.079)$ and no interaction between LPS and PDTC treatment $(P=0.51)$. When EGR1 immunostaining was examined there were significant effects of PDTC treatments on LPS-induced changes in the dentate gyrus, 
the CA1 and CA3 (Fig. 8B). For example, in the CA1 there was a main effect of LPS treatment $\left(F_{1,37}=26.2, P<0.001\right)$ and an interaction between LPS and PDTC treatment $\left(F_{1,37}=6.5, P<0.05\right)$. Post-hoc pairwise analysis reveals that in the DG, CA1 and CA3 that the levels of EGR1 in animals treated with LPS and saline are significantly lower than those treated with LPS and PDTC. When IBA-1 immunostaining was examined by two-way ANOVA, there were significant main effects for LPS $\left(F_{1,37}=24.5, P<0.001\right)$, PDTC $\left(F_{1,37}=22.6, P<0.001\right)$ and an interaction between LPS and PDTC treatment $\left(F_{1,37}=22.1, P<0.001\right)$ in the CA1. In the CA3 there were also main effects of LPS $\left(F_{1,37}=6.1, P<0.05\right)$ and $\operatorname{PDTC}\left(F_{1,37}=6.4\right.$, $P<0.05)$ and an interaction between LPS and PDTC treatment $\left(F_{1,37}=9.9, P<0.01\right)$. In both the CA1 and the CA3 the level of IBA-1 immunostaining in animals treated with both LPS and PDTC was significantly lower than in those animals treated with LPS and saline.

\section{Discussion}

\subsection{Persistent depressive-like and anxiety-like behaviours in sepsis-survivor mice}

This study provides a comprehensive examination of the longlasting effects of LPS-induced sepsis on cognitive, behavioural and neuroimmunological parameters in mice. While several studies have examined sickness behaviour in mice following low dose treatment with LPS, there has been relatively little investigation into the longer-term effects of LPS-induced sepsis. Sepsis-survivor animals exhibited normal movement during open field and watermaze testing indicating no gross impairment to motor skills or locomotion. While post-septic encephalopathy in humans is characterized by both cognitive and affective impairment (Ziaja, 2013), in our study we found that post-septic mice had altered affective behaviours only, with cognitive performance remaining intact in the domains examined. This is in contrast to previous research which has found impaired reference and working memory in the radial arm maze following LPS-induced sepsis (Weberpals et al., 2009), although cognitive impairment in the watermaze present after seven consecutive doses of $5 \mathrm{mg} / \mathrm{kg}$ LPS was recovered 30 days after treatment in another study (Bian et al., 2013). There are some methodological differences between how the 8-arm radial maze task was run in our study compared to that used by Weberpals et al. (2009) - for example differences in number of arms baited and testing at different phases of the light/dark cycle. Sepsis induced via CLP also seems to lead to impairments in learning and memory ten days post-treatment (Barichello et al., 2005, 2007; Comim et al., 2013), and importantly partial recovery of function is present by 30 days and full cognitive recovery after 60 days (Tuon et al., 2008). There is of course the potential for long-lasting sequela of LPS-induced sepsis to vary from those associated with polymicrobial sepsis following CLP, and the severity of sepsis will be increased in CLP models compared to the more moderate LPS-induced sepsis examined here.

In addition to increases in depressive-like behaviours, postseptic animals also exhibited heightened anxiety in the elevated plus maze. Animals surviving CLP-induced sepsis show similarly increased anxiety in the elevated plus maze at 10 days (Calsavara et al., 2012), and somatic anxious (and depressive) symptoms have been shown to be associated with elevated levels of inflammatory factors in among healthy adults (Pitsavos et al., 2006; Hoge et al., 2009). Although no memory impairment, measured by preference percentage, was present in the novel object recognition task, sepsis-survivor mice did in fact show reduced overall exploration when a novel object was introduced as compared with controls. It has been suggested that LPS-induced reduction in object exploration may be a function of lower motivation as well as/in place of cognitive impairment (Haba et al., 2012). It seems likely a reduction in motivation may be present in this model given the other affective changes present in post-septic animals. Sepsis survivors experience high levels of psychosocial and emotional difficulties years after recovering from sepsis itself (Lazosky et al. 2010); for example, 6 months after ICU discharge $56 \%$ of sepsis survivors reported being either moderately or extremely anxious or depressed (Orwelius et al., 2013) and have significantly lower mental health and role-emotional SF-36 scores than the general population (Hofhuis et al., 2008). In our model, increased depressive-like behaviour was present in both the tail suspension test and the sucrose preference test following recovery from sepsis, mirroring some of the long lasting affective changes seen in other sepsis models (Cassol-Jr et al., 2010; Comim et al., 2010). The lack of effect in the forced swim test may reflect the different neural mechanism postulated to regulate performance on the forced swim and tail suspension tests (Cryan et al., 2005).

These results add to a wealth of existing literature on the relationship between inflammation and depressive symptoms both in humans (Dowlati et al., 2010; Mössner et al., 2007) and animals (Wang et al., 2011; You et al., 2011). Both acute (Frenois et al., 2007) and chronic administration of LPS have been shown to produce depressive-like behaviours in mice (Kubera et al., 2013). Importantly, as Wang et al. (2011) and Kubera et al. (2013) showed that depressive behaviour induced by LPS administration could be ameliorated upon fluoxetine administration, we have also shown that an acute treatment with $20 \mathrm{mg} / \mathrm{kg}$ fluoxetine significantly decreases time spent immobile in sepsis-survivor mice. This result indicates that the post-septic model for examining affective changes may have acceptable predictive validity, although further experiments will be required to confirm this (eg. does chronic fluoxetine treatment attenuate anhedonia in post-septic mice). The mechanism by which fluoxetine exerted its antidepressive effects in sepsis-survivor mice is currently unknown, although fluoxetine has previously been shown to exert neuroprotective (Chung et al., 2010; Zhang et al., 2012) and anti-inflammatory (Liu et al., 2011) effects in the presence of LPS stimulated microglia, as well as to significantly reduce mortality upon the i.p. administration of LPS in the lethal range (15-30 mg/kg; Su et al., 2012).

\subsection{Alterations in neuroimmune parameters}

In addition to behavioural alterations present after recovery from sepsis, significant neuroimmune changes also occur within the hippocampus of post-septic animals. Primarily, we note a long-lasting activation of microglia, but not astrocytes, and alterations in the expression of EGR1 and ARC. We also observe reduced hippocampal NPCs in post-septic animals. Of note, at 2 months post-treatment there were no differences between post-septic mice and controls in hippocampal levels of IL-6, TNF- $\alpha$ or IL-1 $\beta$. This is at odds with a number of studies reporting an upregulation of pro-inflammatory cytokines months after LPS-induced sepsis (Bossù et al., 2012; Qin et al., 2007). However these current findings are in agreement with Fan et al. (2012) and Weberpals et al. (2009) who report sustained microglial activation in the absence of astrocytic activation or heightened expression of cytokines TNF- $\alpha$ or IL- $1 \beta$ in the hippocampus one week and two months following LPS-induced sepsis respectively, and are also in agreement with our previous examination of changes in the circadian system following sepsis (O'Callaghan et al., 2012). Therefore, the behavioural alterations present in sepsis-survivor mice do not seem to be the product of an over-expression of inflammatory cytokines in the hippocampus, although this may be occurring in other brain regions. Memory deficits following $10 \mathrm{mg} / \mathrm{kg}$ doses of LPS in rats have been attributed to a significant reduction in the density of 
CA1/CA2 and prefrontal cortex neurons (Semmler et al., 2007). A $5 \mathrm{mg} / \mathrm{kg}$ dose of LPS in mice has been shown to only induce neurodegeneration 7 months after treatment (Qin et al., 2007).

Aside from inflammatory changes we also report a reduction in levels of ARC and EGR1, both regulators of importance in neural plasticity and memory (Bozon et al., 2003; Soulé et al., 2008). Both antigens have also been used as markers of neuronal activity and their transcription has previously been shown to be altered by various forms of LPS administration with differential expression occurring based on animals' age, activity prior to measurement, time of measurement and other factors (Bonow et al., 2009; Rosi, 2011; Rosi et al., 2005). We also note a decrease in the number of proliferating cells within the subgranular zone of the dentate gyrus following sepsis in this model. Acute and chronic treatments with LPS have previously been shown to reduce hippocampal neurogenesis in the rodent hippocampus by reducing both cell proliferation (Fukioka and Akema, 2010; Wu et al., 2013) and the survival of newborn cells (Bastos et al., 2008; Ekdahl et al., 2003). Indeed, an inverse correlation has been observed between the number of microglia present within the hippocampus and NPC proliferation (Gebara et al., 2013). Neurogenesis is strongly implicated in the pathology of affective disorders, although the experimental interruption of neurogenesis in the rodent hippocampus is not by itself always sufficient to produce increased anxiety-like and depressive-like symptoms, with stress appearing to play an important role (Petrik et al., 2012). As we examined BrdU expression after only $24 \mathrm{~h}$ it is unknown whether LPS-induced sepsis affected the survival and differentiation of NPCs or their integration into existing hippocampal networks and future work will need to address such issues.

\subsection{Pre-treatment with PDTC attenuates LPS-induced long-lasting effects}

Pre-treatment with PDTC significantly attenuated the effects of LPS treatment on behavioural and neuroimmune parameters in this model. PDTC has previously shown to inhibit LPS induced I $\mathrm{B} \alpha$ degradation which prevents the translocation of NF- $\kappa B$ dimers to the nucleus and subsequent pro-inflammatory gene transcription (Liu et al., 1999). It has been shown both to improve survival rate and attenuate pro-inflammatory cytokine and iNOS levels following septic doses of LPS (Lauzurica et al., 1999; Meisner et al., 2000; Németh et al., 1998). It should be noted that while numerous studies have used the $200 \mathrm{mg} / \mathrm{kg}$ i.p. dose of PDTC and reported no adverse reactions, the acute reaction to PDTC treatment observed in our study is congruent with a report of nervous system toxicity of PDTC (Chabicovsky et al., 2010). However, we did not observe any long term impairments or alterations in the animals treated with PDTC alone in any measure examined, and are confident that the adverse reactions observed were acute and did not elicit longer-term consequences. PDTC reduced the severity of sepsis induced by LPS and attenuated long-term LPS-induced increases in depressive-like and anxiety-like behaviours. PDTC co-treatment with LPS also lessened LPS-induced long-lasting changes in microglial activation and EGR1 expression to levels similar to controls. PDTC treatment however did not appear to rescue the reduction of NPCs in the hippocampus in LPS treated mice; this finding may be due to the magnitude of sepsis attenuation not being sufficient to significantly impact on the NPC proliferation. While PDTC has not previously been shown to protect against LPS-induced cognitive or affective impairment, it has been shown to protect against cognitive impairment and anxiety-like behaviours in other models involving inflammatory components such as acute restraint stress (Sharma et al., 2011) and neonatal hypoxia-ischemia (Wang et al., 2013).
The current study comprehensively describes the long-lasting behavioural and neuroimmune alterations present in mice following LPS-induced sepsis, although the precise mechanisms through which these changes occur are still unknown. Intact neuron-astrocyte-microglial signalling is essential for normal neuronal circuit structure and homeostasis (Cerbai et al., 2012; Wake et al., 2013) which may be compromised in this model given the elevated levels of activated microglia. Although neither cytokine levels nor NF- $\kappa B$ pathway activation was elevated in the hippocampus of postseptic animals at 2 months post-treatment, microglia may also be detrimental to neuronal function via mechanisms not measured here such as the production of reactive oxygen species (Hernandes et al., 2014), increased indoleamine 2,3-dioxygenase production (Corona et al., 2013), altered chemokine expression (Rivest, 2009) or changes in mitochondrial function (Noh et al., 2014). Weberpals et al. (2009) did show in a very similar model that there was a long-lasting alteration in brain metabolism, which may in part impact on cognitive and behavioural processes. In other studies a $5 \mathrm{mg} / \mathrm{kg}$ dose of LPS does not appear to induce long-lasting neuronal loss, although pre- and post-synaptic protein levels are altered in the hippocampus (Fan et al., 2012; Weberpals et al., 2009) and we show that post-septic mice exhibit reduced levels of IEG proteins essential to synaptic plasticity. The reduction of NPCs produced in post-septic animals in this study may also contribute to this pathology, although attenuating this may not be critical to recover affective behaviour as exhibited.

\section{Conclusion}

In conclusion, this study demonstrates that mice exhibit increased depressive- and anxiety-like behaviours one month after recovery from LPS-induced sepsis, with no long-lasting cognitive impairment. These alterations in affective behaviour coincide with a long lasting upregulation of microglial activation, altered IEG expression and a reduction in the production of NPCs within the hippocampus. Many of these changes are reversed by pre-treatment with NF- $\kappa B$ inhibitor PDTC. Further work is necessary to examine the effects of systemic LPS administration on other key areas involved in affective behaviour (e.g. the amygdala), and the survival, differentiation and incorporation of NPCs into hippocampal networks. Further, the utility of pharmacological intervention in reversing these effects after sepsis induction has occurred should be examined, as should electrophysiological and neuroplastic alterations which may occur in the post-septic brain. All of these factors would allow for a better understanding of post-septic encephalopathy with a view towards addressing the real clinical needs of sepsis survivors.

\section{Appendix A. Supplementary data}

Supplementary data associated with this article can be found, in the online version, at http://dx.doi.org/10.1016/j.bbi.2014.07.007.

\section{References}

Anderson, S.T., O'Callaghan, E.K., Commins, S., Coogan, A.N., 2013. Does prior sepsis alter subsequent circadian and sickness behaviour response to lipopolysaccharide treatment in mice? J. Neural Transm. http://dx.doi.org/ 10.1007/s00702-013-1124-8.

Barichello, T., Martins, M.R., Reinke, A., Constantino, L.S., Machado, R.A., Valvassori, S.S., Dal-Pizzol, F., 2007. Behavioral deficits in sepsis-surviving rats induced by cecal ligation and perforation. Braz. J. Med. Biol. Res. 40 (6), 831-837.

Barichello, T., Martins, M.R., Reinke, A., Feier, G., Ritter, C., Quevedo, J., Dal-Pizzol, F., 2005. Cognitive impairment in sepsis survivors from cecal ligation and perforation. Crit. Care Med. 33 (1), 221-223 (262-263).

Bastos, G.N., Moriya, T., Inui, F., Katura, T., Nakahata, N., 2008. Involvement of cyclooxygenase-2 in lipopolysaccharide-induced impairment of the newborn cell survival in the adult mouse dentate gyrus. Neuroscience 155, 454-462. 
Berk, M., Williams, L.J., Nacka, F.N., O’Neil, A., Pasco, J.A., Moylan, S., Maes, M., 2013. So depression is an inflammatory disease, but where does the inflammation come from? BMC Med. 11, 200.

Beynon, A.L., Thome, J., Coogan, A.N., 2009. Age and time of day influences on the expression of transforming growth factor-beta and phophorylated SMAD3 in the mouse suprachiasmatic and paraventricular nuclei. Neuroimmunomodulat. 16 (6), 392-399.

Bian, Y., Zhao, X., Li, M., Zeng, S., Zhao, B., 2013. Various roles of astrocytes during recovery from repeated exposure to different doses of lipopolysaccharide. Behav. Brain Res. 253, 253-261.

Bonow, R.H., Aïd, S., Zhang, Y., Becker, K.G., Bosetti, F., 2009. The brain expression of genes involved in inflammatory response, the ribosome, and learning and memory is altered by centrally injected lipopolysaccharide in mice. Pharmacogenomics J. 9 (2), 116-126.

Bozon, B., Davis, S., Laroche, S., 2003. A requirement for the immediate early gene zif268 in reconsolidation of recognition memory after retrieval. Neuron 40 (4), 695-701.

Bossù, P., Cutuli, D., Palladino, I., Caporali, P., Angelucci, F., Laricchiuta, D., Petrosini, L., 2012. A single intraperitoneal injection of endotoxin in rats induces longlasting modification in behavior and brain protein levels of TNF- $\alpha$ and IL-18. J. Neuroinflammation 9, 101.

Buras, J.A., Holzmann, B., Sitkovsky, M., 2005. Animal models of sepsis: setting the stage. Nat. Rev. Drug Discov. 4 (10), 854-865.

Calsavara, A.C., Rodrigues, D.H., Miranda, A.S., Costa, P.A., Lima, C.X., Vielela, M.C., Teixeira, A.L., 2012. Late anxiety-like behavior and neuroinflammation in mice subjected to sublethal polymicrobial sepsis. Neurotox. Res. 24 (2), 103-108.

Calsavara, A.C., Rodrigues, D.H., Miranda, A.S., Costa, P.A., Lima, C.X., Vilela, M.C., Teixeira, A.L., 2013. Late anxiety-like behavior and neuroinflamation in mice subjects to sublethal polymicrobial sepsis. Neurotox. Res. 24, 103-108.

Cassol-Jr, O.J., Comim, C.M., Constantino, L.S., Rosa, D.V., Mango, L.A., Stertz, L., Kapczinski, F., Romano-Silva, M.A., Quevedo, J., Dal-Pizzol, F., 2011. Acute low dose of MK-801 prevents memory deficits without altering hippocampal DARPP-32 expression and BDNF levels in sepsis survivor rats. J. Neuroimmunol. 230 (1-2), 48-51.

Cassol-Jr, O.J., Comim, C.M., Petronilho, F., Constantino, L.S., Streck, E.L., Quevedo, J., Dal-Pizzol, F., 2010. Low dose dexamethasone reverses depressive-like parameters and memory impairment in rats submitted to sepsis. Neurosci. Lett. 473 (2), 126-130.

Cerbai, F., Lana, D., Nosi, D., Petkova-Kirova, P., Zecchi, S., Brothers, H.M., Giovannini, M.G., 2012. The neuron-astrocyte-microglia triad in normal brain ageing and in a model of neuroinflammation in the rat hippocampus. PLoS One 7 (9), e45250.

Chabicovsky, M., Prieschl-Grassauer, E., Seipelt, J., Muster, T., Szolar, O.H.J., Hebar, A., Doblhoff-Dier, O., 2010. Pre-clinical safety evaluation of pyrrolidine dithiocarbamate. Basic Clin. Pharmacol. Toxicol. 107 (3), 758-767.

Chang, Y.C., Tsai, M.H., Sheu, W.H., Hsieh, S.C., Chiang, A.N., 2013. The therapeutic potential and mechanisms of action of quercetin in relation to lipopolysaccharide-induced sepsis in vitro and in vivo. PLoS One 8 (11), e80744. http://dx.doi.org/10.1371/journal.pone.0080744.

Chung, E.S., Chung, Y.C., Box, E., Baik, H.H., Park, E.S., Park, J., Jin, B.K., 2010. Fluoxetine prevents LPS-induced degeneration of nigral dopaminergic neurons by inhibiting microglia-mediated oxidative stress. Brain Res. 1363, 143-150.

Comim, C.M., Cassol Jr, O.J., Abreu, I., Moraz, T., Constantino, L.S., Vuolo, F., DalPizzol, F., 2013. Erythropoietin reverts cognitive impairment and alters the oxidative parameters and energetic metabolism in sepsis animal models. J. Neural Transm. 119 (11), 1267-1274.

Comim, C.M., Cassol-Jr, O.J., Constantino, L.C., Petronilho, F., Constantino, L.S., Stertz, L., Kapczinski, F., Barichello, T., Quevedo, J., Dal-Pizzol, F., 2010. Depressive-like parameters in sepsis survivor rats. Neurotox. Res. 17 (3), 279-286.

Corona, A.W., Norden, D.M., Skendelas, J.P., Huang, Y., O'Connor, J.C., Lawson, M., Godbout, J.P., 2013. Indoleamine 2,3-dioxygenase inhibition attenuates lipopolysaccharide induced persistent microglial activation and depressivelike complications in fractalkine receptor (CX(3)CR1)-deficient mice. Brain Behav. Immun., 134-142.

Cryan, J.F., Mombereau, C., Vassout, A., 2005. The tail suspension test as a model for assessing antidepressant activity: review of pharmacological and genetic studies in mice. Neurosci. Biobehav. R. 29 (4-5), 571-625.

Davydow, D.S., Hough, C.L., Langa, K.M., Iwashyna, T.J., 2012. Presepsis depressive symptoms are associated with incident cognitive impairment in survivors of severe sepsis: a prospective cohort study of older Americans. J. Am. Geriatr. Soc. 60 (12), 2290-2296

Deacon, R.M., 2006. Digging and marble burying in mice: simple methods for in vivo identification of biological impacts. Nat. Protoc. 1 (1), 122-124.

Deacon, R.M., 2011. Hyponeophagia: a measure of anxiety in the mouse. J. Vis. Exp. (51), e2613. http://dx.doi.org/10.3791/2613.

Doi, K., Leelahavanichkul, A., Yuen, P.S., Star, R.A., 2009. Animal models of sepsis and sepsis-induced kidney injury. J. Clin. Invest. 119 (10), 3868-3878.

Dowlati, Y., Herrmann, N., Swardfager, W., Liu, H., Sham, L., Reim, E.K., Lancôt, K.L., 2010. A meta-analysis of cytokines in major depression. Biol. Psychiatry 67, 446-457.

Ekdahl, C.T., Claasen, J., Bonde, S., Kokaia, Z., Lindvall, O., 2003. Inflammation is detrimental for neurogenesis in adult brain. Proc. Natl. Acad. Sci. U.S.A. 100 (23), $13632-13637$

Fan, K., Wu, X., Fan, B., Li, N., Lin, Y., Yao, Y., Ma, J., 2012. Up-regulation of microglial cathepsin $C$ expression and activity in lipopolysaccharide-induced neuroinflammation. J. Neuoinflammation 9, 96.
Franklin, K., Paxinos, G., 1997. The Mouse Brain in Stereotaxic Coordinates. Academic Press, San Diego.

Frenois, F., Moreau, M., O’Connor, J., Lawson, M., Micon, C., Lestage, J., Castanon, N. 2007. Lipopolysaccharide induces delayed FosB/DeltaFosB immunostaining within the mouse extended amygdala, hippocampus and hypothalamus, that parallel the expression of depressive-like behavior. Psychoneuroendocrinology 32 (5), 516-531.

Fukioka, H., Akema, T., 2010. Lipopolysaccharide acutely inhibits proliferation of neural precursor cells in the dentate gyrus. Brain Res. 1352, 35-42.

Gebara, E., Sultan, S., Kocher-Braissant, J., Toni, N., 2013. Adult hippocampal neurogenesis inversely correlates with microglia in conditions of voluntary running and aging. Front. Neurosci. 7 (145), 1-9.

Haba, R., Shintani, N., Onaka, Y., Wang, H., Takenaga, R., Hayata, A., Hashimoto, H., 2012. Lipopolysaccharide affects exploratory behaviors toward novel objects by impairing cognition and/or motivation in mice: possible role of activation of the central amygdala. Behav. Brain Res. 228 (2), 423-431.

Hernandes, M.S., Avila, J.C., Trevelin, S.C., Reis, P.A., Kinjo, E.R., Lopes, L.R., Bozza F.A., 2014. The role of Nox2-dervied ROS in the development of cognitive impairment after sepsis. J. Neuroinflammation 11 (36). http://dx.doi.org/ 10.1186/1742-2094-11-36.

Hofhuis, J.G., Spronk, P.E., van Stel, H.F., Schrijvers, A.J., Rommes, J.H., Bakker, J., 2008. The impact of severe sepsis on health-related quality of life: a long-term follow-up study. Crit. Care Trauma 107 (6), 1957-1964.

Hoge, E.A., Brandstetter, K., Moshier, S., Pollack, M.H., Wong, K.K., Simon, N.M., 2009 Broad spectrum of cytokine abormalities in panic disorder and posttraumatic stress disorder. Depress. Anxiety 26 (5), 447-455.

Iwashyna, T.J., Ely, E.W., Smith, D.M., Langa, K.M., 2010. Long-term cognitive impairment and functional disability among survivors of severe sepsis. J. Am. Med. Assoc. 304 (16), 1787-1794.

Jacob, A., Brorson, J.R., Alexander, J.J., 2011. Septic encephalopathy: inflammation in man and mouse. Neurochem. Int. 58 (4), 472-476.

Janitzky, K., Schwegler, H., Kröber, A., Roskoden, T., Yanagawa, Y., Linke, R., 2011 Species-relevant inescapable stress differently influences memory consolidation and retrieval of mice in a spatial radial arm maze. Behav. Brain Res. 219 (1), 142-148.

Kubera, M., Curzytek, K., Weronika, D.L., Basta-Kaim, A., Budziszewska, B., Roman, A., Maes, M., 2013. A new animal model of (chronic) depression induced by repeated and intermittent lipopolysaccharide administration for 4 months Brain Behav. Immun. 31, 96-104.

Lauzurica, P. Martínez-Martínez, S., Marazuela, M., Gómez del Arco, P. Martínez-A C., Sánchez-Madrid, F., Redondo, J.M., 1999. Pyrrolidine dithiocarbamate protects mice from lethal shock induced by LPS or TNF- $\alpha$. Eur. J. Immunol. 29 (6), 1890-1900.

Lazosky, A., Young, G.B., Zirul, S., Philips, R., 2010. Quality of life after septic illness. J Crit. Care 25 (3), 406-412.

Lin, L., Chen, Y., Lee, W., Chen, H., Yang, R., 2010. Heat shock pretreatment attenuates sepsis-associated encephalopathy in LPS-induced septic rats. Brain Dev. 32 (5), 371-377.

Liu, D., Wang, Z., Liu, S., Wang, F., Zhao, S., Hao, A., 2011. Anti-inflammatory effects of fluoxetine in lipopolysaccharide(LPS)-stimulated microglial cells Neuropharmacology 61 (4), 592-599.

Liu, S.F., Ye, X., Malik, A.B., 1999. Pyrrolidine dithiocarbamate prevents I-КB degradation and reduces microvascular injury induced by lipopolysaccharide in multiple organs. Mol. Pharmacol. 55 (4), 658-667.

Meisner, M., Schmidt, J., Schywalsky, M., Tschaikowsky, K., 2000. Influence of pyrrolidine dithiocarbamate on the inflammatory response in macrophages and mouse endotoxin shock. Int. J. Immunopharmacol. 22 (1), 83-90.

Miller, A.H., Maletic, V., Raison, C.L., 2009. Inflammation and its discontents: the role of cytokines in the pathophysiology of major depression. Biol. Psychiatry 65 (9), 732-741.

Mössner, R., Mikova, O., Koutsilieri, E., Saoud, M., Ehlis, A.-C., Müller, N., Riederer, P. 2007. Consensus paper of the WFSBP task force on biological markers: biological markers in depression. World J. Biol. Psychiatry 8 (3), 141-174.

Németh, Z.H., Haskó, G., Viz, i.E., 1998. Pyrrolidine dithiocarbamate augments IL-10, inhibits TNF-alpha, MIP-1alpha, IL-12, and nitric oxide production and protects from the lethal effect of endotoxin. Shock 10 (1), 49-53.

Noh, H., Jeon, J., Seo, H., 2014. Systemic injection of LPS induces region-specific neuroinflammation and mitochondrial dysfunction in normal mice brain. Neurochem. Int. http://dx.doi.org/10.1016/j.neuint.2014.02.008.

O'Callaghan, E.K., Anderson, S.T., Moynagh, P.N., Coogan, A.N., 2012. Long-lasting effects of sepsis on circadian rhythms in the mouse. PLoS One 7 (10).

Okazaki, S., Tachibana, Y., Koga-Ogawa, Y., Takeshita, K., 2014. Redox evaluation in sepsis model mice by the in vivo ESR technique using acyl-protected hydroxylamine. Free Radical Biol. Med. 68, 72-79.

Orwelius, L., Lobo, C., Teixeira Pinto, A., Carneiro, A., Costa-Pereira, A., Granja, C., 2013. Sepsis patients do not differ in health-related quality of life compared with other ICU patients. Acta Anaesthesiol. Scand. 57 (9), 1201-1205.

Papadopoulous, M.C., Davies, D.C., Moss, R.F., Tighe, D., Bennett, E.D., 2000. Pathophysiology of septic encephalopathy: a review. Crit. Care Med. 8, 30193024.

Petrik, D., Lagace, D.C., Eisch, A.M., 2012. The neurogenesis hypothesis of affective and anxiety disorders: are we mistaking the scaffolding for the building. Neuropharmacology 62 (1), 21-34.

Pitsavos, C., Panagiotakos, D.B., Papageorgious, C., Tsetsekou, E., Soldatos, C., Stefanadis, C. 2006. Anxiety in relation to inflammation and coagulation 
markers, among healthy adults: the ATTICA Study. Athersclerosis 1285, 320326.

Porsolt, R.D., Bertin, A., Jalfre, M., 1997. Behavioral despair in mice: a primary screening test for antidepressants. Arch. Int. Pharmacodyn. Ther. 229, 327-336.

Oin, L., Wu, X., Block, M.L., Liu, Y., Breese, G.R., Hong, J.S., Crews, F.T. 2007. Systemic LPS causes chronic neuroinflammation and progressive neurodegeneration. Glia 55 (5), 453-462.

Rivest, S., 2009. Regulation of innate immune responses in the brain. Nat. Rev. Immunol. 9, 429-439.

Robertson, C.M., Coopersmith, C.M., 2006. The systemic inflammatory response syndrome. Microbes Infect. 8 (5), 1382-1389.

Rosi, S., 2011. Neuroinflammation and the plasticity-related immediate-early gene Arc. Brain Behav. Immun. 25 (Suppl. 1), S39-S49.

Rosi, S., Ramirez-Amaya, V., Vazdarjanova, A., Worley, P.F., Barnes, C.A., Wenk, G.L., 2005. Neuroinflammation alters the hippocampal pattern of behaviourally induced Arc expression. J. Neurosci. 25 (3), 723-731.

Semmler, A., Frisch, C., Debeir, T., Ramanathan, M., Okulla, T., Klockgether, T., THM, 2007. Long-term cognitive impairment, neuronal loss and reduced cortical cholinergic innervation after recovery from sepsis in a rodent model. Exp. Neurol. 204 (2), 733-740.

Semmler, A., Widmann, C.N., Okulla, T., Urbach, H., Kaiser, M., Widman, G., THM, 2013. Persistent cognitive impairment, hippocampal atrophy and EEG changes in sepsis survivors. J. Neurol. Neurosurg. Psychiatry 84, 62-70.

Sharma, V., Gilhotra, R., Dhingra, D., Gilhotra, N., 2011. Possible underlying influence of $\mathrm{p} 38 \mathrm{MAPK}$ and $\mathrm{NF}-\mathrm{KB}$ in the diminished anti-anxiety effect of diazepam in stressed mice. J. Pharmacol. Sci. 116 (3), 257-263.

Soulé, J., Penke, Z., Kanhema, T., Alme, M.N., Laroche, S., Bramham, C.R., 2008 Object-place recognition learning triggers rapid induction of plasticity-related immediate early genes and synaptic proteins in the rat dentate gyrus. Neural Plast. http://dx.doi.org/10.1155/2008/269097 (Article ID 269097).

Steru, L., Chermat, R., Thierry, B., Simon, P., 1985. The tail suspension test: a new method for screening antidepressants in mice. Psychopharmacology 367, 367 370.

Strekalova, T., Spanagel, R., Bartsch, D., Henn, F.A., Gass, P., 2004. Stress-induced anhedonia in mice is associated with deficits in forced swimming and exploration. Neuropsychopharmacology 29 (11), 2007-2017.

Su, H., Ma, C., Yu, B., Chien, Y., Tsai, C., Huang, W., Tsao, C., 2012. Glycogen synthase kinase-3 $\beta$ regulates anti-inflammatory property of fluoxetine. Int. Immunopharmacol. 14 (2), 150-156.
Tuon, L., Comim, C.M., Petronilho, F., Barichello, T., Izquierdo, I., Quevedo, Q., DalPizzol, 2008. Time-dependent behavioral recovery after sepsis in rats. Intensive Care Med. 34 (9), 1724-1731.

Vorhees, C.V., Williams, M.T., 2006. Morris water maze: procedures for assessing spatial and related forms of learning and memory. Nat. Protoc. 1 (2), 848-858.

Wake, H., Moorhouse, A.J., Miyamoto, A., Nabekura, J., 2013. Microglia: actively surveying and shaping neuronal circuit structure and function. Trends Neurosci. 36 (4), 209-217.

Walf, A.A., Frye, C.A., 2007. The use of the elevated plus maze as an assay of anxietyrelated behavior in rodents. Nat. Protoc. 2, 322-328.

Wang, Y., Cui, X.L., Liu, Y.F., Gao, F., Wei, D., Li, X.W., Wang, H.N., Tan, Q.R., Jiang, W., 2011. LPS inhibits the effects of fluoxetine on depression-like behaviour and hippocampal neurogenesis in rats. Prog. Neuropsychopharmacol. Biol. Psychiatry 35 (8), 1831-1835.

Wang, Z., Zhao, H., Peng, S., Zuo, Z., 2013. Intranasal pyrrolidine dithiocarbamate decreases brain inflammatory mediators and provides neuroprotection after brain hypoxia-ischemia in neonatal rats. Exp. Neurol. 249, 74-82.

Weberpals, M., Hermes, M., Hermann, S., Kummer, M.P., Terwel, D., Semmler, A., Heneka, M.T., 2009. NOS2 Gene deficiency protects from sepsis-induced longterm cognitive deficits. J. Neurosci. 29 (45), 14177-14184.

Winters, B.D., Eberlein, M.E., Leung, J., Needham, D.M., Pronovost, P.J., Sevransky, J.E., 2010. Long-term mortality and quality of life in sepsis: a systematic review. Crit. Care Med. 38 (5), 1276-1283.

Wojtowicz, J.M., Kee, N., 2006. BrdU assay for neurogenesis in rodents. Nat. Protoc. 1 (3), 1399-1405.

Wu, G., Matsuwaki, T., Tanaka, Y., Yamanouchi, K., Hu, J., Nishihara, M., 2013. Taurine counteracts the suppressive effect of lipopolysaccharide on neurogenesis in the hippocampus of rats. Adv. Exp. Med. Biol. 775, 111-119.

You, Z., Luo, C., Zhang, W., Chen, Y., He, J., Zhao, Q., Wu, Y., 2011. Pro- and antiinflammatory cytokines expression in rat's brain and spleen exposed to chronic mild stress: Involvement in depression. Behav. Brain Res. 225 (1), 135-141.

Zhang, F., Zhou, H., Wilson, B.C., Shi, J., Hong, J., Gao, H., 2012. Fluoxetine protects neurons against microglial activation-mediated neurotoxicity. Proceedings of WFN XIX World Congress on Parkinson's Disease and Related Disorders 18(1) (pp. S213-S217). Parkinsonism \& Related Disorders.

Ziaja, M., 2013. Septic encephalopathy. Curr. Neurol. Neurosci. Rep. 13, 383. 